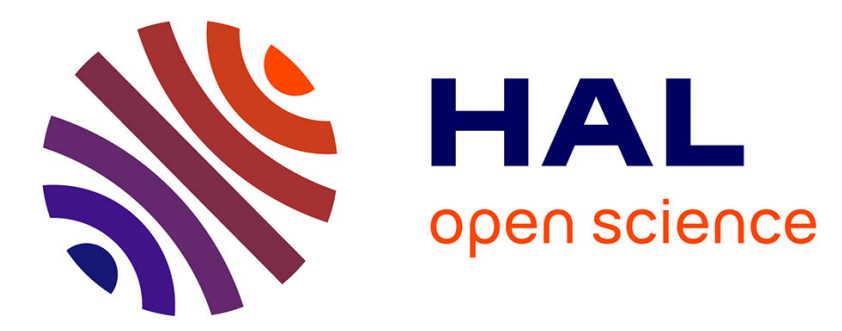

\title{
Orientational disorder in the high temperature phase of $\mathrm{KCIO} 4$
}

\author{
B. Denise, M. Debeau, Ph. Depondt, G. Heger
}

\section{To cite this version:}

B. Denise, M. Debeau, Ph. Depondt, G. Heger. Orientational disorder in the high temperature phase of KCIO4. Journal de Physique, 1988, 49 (7), pp.1203-1210. 10.1051/jphys:019880049070120300 . jpa-00210802

\section{HAL Id: jpa-00210802 https://hal.science/jpa-00210802}

Submitted on 1 Jan 1988

HAL is a multi-disciplinary open access archive for the deposit and dissemination of scientific research documents, whether they are published or not. The documents may come from teaching and research institutions in France or abroad, or from public or private research centers.
L'archive ouverte pluridisciplinaire HAL, est destinée au dépôt et à la diffusion de documents scientifiques de niveau recherche, publiés ou non, émanant des établissements d'enseignement et de recherche français ou étrangers, des laboratoires publics ou privés. 
Classification

Physics Abstracts

61.12

\title{
Orientational disorder in the high temperature phase of $\mathrm{KClO}_{4}$
}

\author{
B. Denise, M. Debeau (*), Ph. Depondt and G. Heger $\left(^{* *, 1}\right)$ \\ Département de Recherches Physiques, Unité associée au C.N.R.S. ${ }^{\circ} 71$, Université Pierre et Marie Curie, \\ 4 place Jussieu, 75252 Paris Cedex 05, France \\ (1) Kernforschungzentrum Karlsruhe, Institut für Nukleare Festkörperphysik, Postfach 3640, 7500 Karlsruhe, \\ F.R.G.
}

(Reçu le $1^{\text {er }}$ décembre 1987, accepté le 8 mars 1988)

\begin{abstract}
Résumé. - Un monocristal de la phase à haute température de $\mathrm{KClO}_{4}$ a été étudié par diffraction de neutrons, à $325^{\circ} \mathrm{C}$ et $420^{\circ} \mathrm{C}$. L'analyse du facteur de structure des réflexions de Bragg conduit à la fonction statique de densité de probabilité d'orientation. La position des maximums de cette fonction montre que les ions $\mathrm{ClO}_{4}^{-}$ont des orientations privilégiées de symétrie $\mathrm{T}_{\mathrm{d}}$, avec deux positions possibles. Ce résultat est comparé avec ceux d'articles antérieurs. On suggère aussi que les ions pourraient effectuer des rotations non instantanées autour des axes quaternaires du cube.
\end{abstract}

\begin{abstract}
Neutron diffraction experiments have been performed on a single crystal of the high-temperature phase of $\mathrm{KClO}_{4}$ at $325^{\circ} \mathrm{C}$ and $420^{\circ} \mathrm{C}$. The analysis of the structure factor of Bragg reflections leads to the static orientational probability density function. The positions of the maxima of this function show that $\mathrm{ClO}_{4}^{-}$ions have preferred orientations of $\mathrm{T}_{\mathrm{d}}$ symmetry, with two possible positions. Comparison is made of this result with previous papers. It is also suggested that the ions could reorient between the two potential wells mainly by non-instantaneous rotations around the four-fold axes of the cube.
\end{abstract}

\section{Introduction.}

It has been known for many years that potassium perchlorate, $\mathrm{KClO}_{4}$, exhibits a transition between two crystallographic phases. Below $T_{\mathrm{tr}}=310^{\circ} \mathrm{C}$, the structure is orthorhombic [1] $\left(\mathrm{D}_{2 \mathrm{~h}}^{16}\right.$-Pnma) and is facecentered cubic [2] $\left(\mathrm{O}_{\mathrm{h}}^{5}-\mathrm{Fm} 3 \mathrm{~m}\right)$ above $T_{\mathrm{tr}}$. The transition has all the characteristics of a first-order transition between an ordered and an orientationally disordered phases : strong hysteresis, important volume change $(11 \%)$ of the unit cell at the transition. In the cubic phase, the $\mathrm{ClO}_{4}^{-}$ions are disordered (a situation usually referred to as ODIC : orientational disorder in crystals), and reorient dynamically between several orientations.

One possible approach to study this kind of disorder is to determine the static orientational probability density function $P_{0}(\Omega)$ [3]. This function

$\left(^{*}\right)$ Author to whom correspondence should be addressed.

(**) Present address : Laboratoire Léon Brillouin (C.E.A.-C.N.R.S.), C.E.N.-Saclay, 91191 Gif-sur-Yvette Cedex, France. represents the probability for an ion to be in a given orientation with respect to the symmetry elements of the crystal, and thus gives the symmetries and the number of the potential wells between which the ions can reorient. Its maxima usually correspond to orientations such that the ion and the crystal have two or more symmetry elements in common. For a tetrahedron in a cube, there are four such possible point groups [4]: $T_{d}$ with 2 different orientations, $D_{2 d}$ with 6 orientations, $C_{3 v}$ with 8 orientations, $\mathrm{C}_{2 \mathrm{v}}$ with 12 orientations.

In 1983, two papers gave different results concerning the most probable orientation of the $\mathrm{ClO}_{4}^{-}$ions in the disordered phase : Toupry et al. [5] concluded, from Raman scattering experiments, that $P_{0}(\Omega)$ should have maxima corresponding to orientations $\mathrm{C}_{3 \mathrm{v}}$. Klein et al. [6] obtained, from a molecular dynamics simulation, $T_{d}$ orientations in agreement with Pistorius' assumption [2]. This contradiction lead us to measure $P_{0}(\Omega)$ by the most direct method, that is through a neutron diffraction experiment, because the structure factor of Bragg reflections contains directly $P_{0}(\Omega)$, as we will see in section 3. 


\section{Experiment.}

The structure of the high-temperature phase of $\mathrm{KClO}_{4}$ has been determined from experiments performed on the four-circles diffractometer $5 \mathrm{C} 2$ on the hot source of the Orphée reactor at Léon Brillouin Laboratory ( $\left.{ }^{1}\right)$ (CEN-Saclay). The wavelength of the incident neutron beam is $0.832 \AA$. Two crystals have been used. They were grown by the silica gel technique and have been provided by Venkateswara Rao [7]. They were of excellent optical quality and showed, during the experiment, very small mosaicity in the room temperature phase.

The first crystal was heated very slowly $\left(0.5^{\circ} \mathrm{C}\right.$ per minute). During heating, two Bragg reflections of the orthorhombic phase have been recorded repeatedly. These two reflections had been chosen in the following way: Toupry et al. had proposed a relationship between the structures of the two phases, namely $a_{\text {orth }}$ and $b_{\text {orth }}$ are parallel to the diagonals of a face of the cube and such that $a_{\text {orth }} \simeq a \sqrt{2}$ ( $a=$ parameter of the cubic cell) and $b_{\text {orth }} \simeq a / \sqrt{2}, c_{\text {orth }}$ being parallel to an edge of the cube with $c_{\text {orth }} \simeq a$. If their hypothesis had been correct, one of the two reflections chosen, (040) orth should have remained in the cubic phase, becoming $(440)_{\text {cub }}$, while the other (333) orth should have disappeared at the transition. It happened that the result did not correspond to their hypothesis : the (333) orth reflection disappeared and a Bragg reflection was detected very close to the original position of $(040)_{\text {orth }}$. But this reflection was found to be, not a (440), but a (333) reflection of the cubic phase. We also checked that the crystal was no more a single crystal and was made of at least two crystals.

The second crystal was heated much faster $\left(10^{\circ} \mathrm{C}\right.$ per minute). Again two reflections (040) orth and (333) orth were followed during heating and both disappeared at the transition temperature. In the cubic phase, the crystal broke into four crystals, one of them much larger than the others. None of these four crystals had an orientation which could be deduced from the scheme proposed by Toupry et al., and these orientations were also different from those found in the first crystal. In neither case, a simple relation could be found between the orientations of the crystals.

This means that the transition occurs with a complete reconstruction of the structure in an unpredictable way with respect to the low-temperature structure. Such effect is usual when there is no possible group theory relationship between the two phases i.e. when one structure cannot be considered as a subgroup of the other, or when the two structures are not subgroups of a real or hypothetical mother structure. This is the case, for instance, in

(1) C.E.A. and C.N.R.S. laboratory. the reconstructive transition from the f.c.c. to the b.c.c. structure. On the contrary, in the present case, Pnma is a subgroup of Fm $3 \mathrm{~m}$. We are here in the less usual case where the strong first order character of the transition impedes, when passing from the less symmetric to the more symmetric phase, any relationship between the two structures. It may be possible to relate the reconstructive nature of the transition and the increase of the transition temperature when the rate of heating decreases : this temperature was, indeed, $320^{\circ} \mathrm{C}$ for heating at $10{ }^{\circ} \mathrm{C}$ per minute and $390^{\circ} \mathrm{C}$ for heating at $0.5^{\circ} \mathrm{C}$ per minute.

We made a refined structure analysis, using the largest of the four crystals, and recorded Bragg reflections at $325^{\circ} \mathrm{C}$ and $420^{\circ} \mathrm{C}$. As always in ODIC crystals, very few reflections have been recorded (32 independent reflexions) due to the fast decrease of intensity when the wave vector increases.

\section{Structure of the high-temperature phase : first model.}

We first checked that the structure of $\mathrm{KClO}_{4}$ in the high temperature phase was indeed face-centered cubic. The cell parameter was found to be $a=$ $7.522 \pm 0.002 \AA$ at $325^{\circ} \mathrm{C}$ and increased up to $a=7.58 \pm 0.01 \AA$ at $420^{\circ} \mathrm{C}$.

The mean positions of the $\mathrm{K}$ and of the $\mathrm{Cl}$ atoms are fixed by symmetry and will not be refined. The $\mathrm{ClO}_{4}^{-}$tetrahedron is supposed to be regular so that the knowledge of the mean position of one oxygen atom or of the direction and the length of one $\mathrm{Cl}-\mathrm{O}$ bond is sufficient to determine the structure. The now well known method of Press and Hüller [3] was used to calculate the structure factor $F(\mathbf{Q})$ of the Bragg reflections, which includes the static orientational probability density function $P_{0}(\Omega) ; \Omega$ represents the Euler angles associated with the rotation which brings the crystal axes in coincidence with the molecular axes. $P_{0}(\Omega)$ can be expanded on the basis of functions $R_{\lambda \lambda^{\prime}}^{l}(\Omega)$ (cubic rotators) adapted to the symmetries of the ion and of the crystalline site :

$$
P_{0}(\Omega)=\frac{1}{8 \pi^{2}} \sum_{l, \lambda, \lambda^{\prime}}(2 l+1) A_{\lambda \lambda^{\prime}}^{l} R_{\lambda \lambda^{\prime}}^{l}(\Omega)
$$

The structure factor is a sum of two terms : one for $\mathrm{K}^{+}$ions including the Debye-Waller factor $\exp \left(-W_{\mathrm{K}^{+}}(\mathbf{Q})\right)$, the other is the product of the Debye-Waller factor for $\mathrm{ClO}_{4}^{-}$ions, $\exp \left(-W_{\mathrm{ClO}_{4}^{-}}(\mathbf{Q})\right)$, of a phase term due to the choice of origin on $\mathrm{K}^{+}$, and of a rotational term $F_{\text {rot }}(\mathbf{Q})$ :

$$
\begin{gathered}
F(\mathbf{Q})=f_{\mathrm{K}^{+}} \exp \left(-\frac{1}{2} Q^{2}\left\langle u_{x}^{2}\right\rangle_{\mathrm{K}^{+}}\right)+\exp \left(i \mathbf{R}_{\mathrm{Cl}} \cdot \mathbf{Q}\right) \times \\
\quad \times \exp \left(-\frac{1}{2} Q^{2}\left\langle u_{x}^{2}\right\rangle_{\mathrm{ClO}_{4}^{-}}\right) \cdot F_{\mathrm{rot}}(\mathbf{Q}) .
\end{gathered}
$$


In this formula

Q is the scattering vector;

$f_{n} \quad$ is the scattering cross-section of the atom $n$;

$\left\langle u^{2}\right\rangle$ is the isotropic mean displacement of an ion $=3\left\langle u_{x}^{2}\right\rangle$;

$\mathbf{R}_{\mathrm{Cl}}$ is the position of the $\mathrm{Cl}$ atom if the origin is taken on $\mathrm{K}^{+}$.

From [3],

$F_{\text {rot }}(\mathbf{Q})=f_{\mathrm{Cl}}+4 f_{0}\left[4 \pi \sum_{l, \lambda} c_{\lambda}^{l} J_{l}(Q \rho) K_{\lambda}^{l^{*}}(\mathbf{Q})\right]$

where

$J_{l}(Q \rho)$ is the spherical Bessel function of order $l$ $\rho \quad$ is the $\mathrm{Cl}-\mathrm{O}$ distance

$K_{\lambda}^{l} \quad$ is a cubic harmonics

$c_{\lambda}^{l} \quad$ is the orientational probability density of the oxygen atoms in the reference frame of the crystal. It can be expanded, with the help of equation (1), as :

$$
c_{\lambda}^{l}=\sum_{\lambda^{\prime}} A_{\lambda \lambda^{\prime}}^{l} b_{\lambda^{\prime}}^{l}
$$

where $b_{\lambda}^{l}$, is the orientational probability density of the oxygen atoms in the molecular reference frame :

$$
b_{\lambda^{\prime}}^{l}=K_{\lambda^{\prime}}^{l}\left(\theta_{0}, \phi_{0}\right)
$$

where $\theta_{0}, \phi_{0}$ are the spherical angles defining the direction of one oxygen atom in the molecular frame.

Finally,

$$
\begin{aligned}
F_{\text {rot }}(\mathbf{Q}) & =f_{\mathrm{Cl}}+4 f_{0} \times \\
& \times\left[4 \pi \sum_{l, \lambda, \lambda^{\prime}} A_{\lambda \lambda^{\prime}}^{l} b_{\lambda^{\prime}}^{l} J_{l}(Q \rho) K_{\lambda}^{l^{*}}(\mathbf{Q})\right] .
\end{aligned}
$$

Using these formulas, the structure factor is easily calculated : $K_{\lambda}^{l}(\mathbf{Q}), J_{l}(Q \rho)$ and $b_{\lambda^{\prime}}^{l}$ are either tabu- lated $[8,9]$ or calculated from the structure of the ion. $A_{\lambda \lambda^{\prime}}^{l}$ and $\left\langle u_{x}^{2}\right\rangle$ are adjusted as parameters so that $\left|F(\mathbf{Q})_{\text {calc }}\right|=\sqrt{F^{2}(\mathbf{Q})_{\text {obs }}}$. Then the knowledge of the maxima of $P_{0}(\Omega)$ is straightforward.

The distance $\mathrm{Cl}-\mathrm{O}$ was first refined and was found to vary between $1.47 \AA$ and $1.51 \AA$ depending on the total number of parameters. It was then fixed at $1.5 \AA$, an average value compatible with the estimated standard deviations obtained in the first set of refinements. The last least-squares fit was performed with 9 parameters (a normalization factor, $4 A_{\lambda \lambda^{\prime}}^{l}$, $2\left\langle u^{2}\right\rangle$, and 3 correlation factors defined at the end of this paragraph), which is the number of parameters used in the second model (see paragraph (5)). Table I gives the result at $325^{\circ} \mathrm{C}$, with a reliability factor $R_{\mathrm{w}}=4.6 \%(R=8.7 \%)$.

Because of the invariance of $P_{0}(\Omega)$ with respect to the symmetry operations of the site group and of the molecular group [10], only a few $A_{\lambda \lambda^{\prime}}^{l}$ are not equal to zero. In the case of $\mathrm{ClO}_{4}^{-}$ions (symmetry $\mathrm{T}_{\mathrm{d}}$ in site $\mathrm{O}_{\mathrm{h}}$ ), the first non zero coefficients are : $A_{11}^{4}, A_{11}^{6}, A_{11}^{8}, A_{11}^{10}$ and so on. $A_{11}^{0}$ is taken to be equal to 1 (normalization condition).

\section{Discussion of the first model.}

Table II gives the values of the coefficients fitted in the calculation of the structure factor of $\mathrm{KClO}_{4}$ at $325^{\circ} \mathrm{C}$ and $420^{\circ} \mathrm{C}$. They are all positive or nearly equal to zero. This is a strong indication that the $\mathrm{ClO}_{4}^{-}$ions have preferred orientations with $\mathrm{T}_{d}$ symmetry, with two possible positions, because when the coefficients are calculated for a $P_{0}(\Omega)$ corresponding to one of the ideal positions recalled in the introduction, they are found to be [11] all positive (and equal to 1 ) only for $T_{d}$ orientations.

The values obtained for the non zero coefficients are, nevertheless, smaller than they would be in the ideal $T_{d}$ case, which means that the disorder is more

Table I. - Comparison between the structure factors: $F_{\mathrm{obs}}$ : observed; $\sigma_{\mathrm{obs}}$ : standard deviations; $P_{0}(\Omega)$ : calculated from the first model; $32 f$ : calculated from the second model.

\begin{tabular}{|l|c|c|c|c|c|c|c|c|c|c|c|c|c|c|}
\hline$h k l$ & $F_{\text {obs }}$ & $\sigma_{\text {obs }}$ & {$\left[P_{0}(\Omega)\right]$} & {$[32 f]$} & $h k l$ & $F_{\text {obs }}$ & $\sigma_{\text {obs }}$ & {$\left[P_{0}(\Omega)\right]$} & {$[32 f]$} & $h k l$ & $F_{\text {obs }}$ & $\sigma_{\text {obs }}$ & {$\left[P_{0}(\Omega)\right]$} & {$[32 f]$} \\
\hline 111 & 13.32 & 0.45 & 13.47 & 13.45 & 440 & 5.97 & 0.15 & 6.13 & 5.99 & 642 & 2.26 & 0.13 & 1.83 & 2.26 \\
200 & 14.73 & 0.50 & 14.77 & 14.78 & 531 & 3.22 & 0.13 & 3.01 & 3.17 & 553 & 0.92 & 0.12 & 0.68 & 1.09 \\
220 & 9.12 & 0.22 & 8.54 & 8.94 & 600 & 4.11 & 0.14 & 4.17 & 4.00 & 731 & 1.31 & 0.12 & 0.90 & 1.40 \\
311 & 0 & 0.09 & 0.47 & 0.73 & 442 & 5.29 & 0.15 & 5.13 & 5.17 & 800 & 2.45 & 0.13 & 2.2 & 2.38 \\
222 & 7.58 & 0.18 & 7.51 & 7.67 & 620 & 3.94 & 0.14 & 3.93 & 4.09 & 733 & 0 & 0.15 & 0.35 & 0.83 \\
400 & 0.80 & 0.21 & 1.20 & 0.91 & 533 & 2.37 & 0.12 & 1.99 & 2.37 & 644 & 1.53 & 0.14 & 0.97 & 1.28 \\
331 & 2.95 & 0.08 & 3.26 & 3.03 & 622 & 3.55 & 0.14 & 3.23 & 3.57 & 820 & 1.57 & 0.14 & 1.48 & 1.79 \\
420 & 4.29 & 0.09 & 4.64 & 4.29 & 444 & 2.74 & 0.14 & 2.66 & 2.97 & 822 & 1.35 & 0.12 & 1.03 & 1.39 \\
422 & 5.72 & 0.11 & 6.05 & 5.72 & 711 & 2.30 & 0.11 & 1.98 & 2.26 & 660 & 1.42 & 0.12 & 1.08 & 1.33 \\
511 & 0.81 & 0.08 & 1.28 & 1.14 & 551 & 2.08 & 0.11 & 1.68 & 2.11 & 751 & 0 & 0.15 & 0.41 & 0.73 \\
& & & & & & & & & & & & & $4.6 \%$ & $2.3 \%$ \\
333 & 4.15 & 0.09 & 4.28 & 4.11 & 640 & 2.82 & 0.11 & 2.59 & 3.01 & $R_{\mathrm{w}}$ & $=$ & & $4.6 \%$ & \\
\hline
\end{tabular}


Table II. - Parameters of the first model.

$$
\begin{array}{cccc}
T & A_{11}^{4} & A_{11}^{6} & A_{11}^{8} \\
- & - & - & - \\
325^{\circ} \mathrm{C} & 0.44 \pm 0.03 & 0.07 \pm 0.02 & 0.45 \pm 0.17 \\
& 0.44 \pm 0.03 & 0.07 \pm 0.02 & 0.43 \pm 0.17 \\
420^{\circ} \mathrm{C} & 0.41 \pm 0.03 & 0.05 \pm 0.02 & 0.35 \pm 0.19 \\
& 0.41 \pm 0.03 & 0.05 \pm 0.03 & 0.36 \pm 0.20
\end{array}
$$

complex : even if these orientations are preferred, an important fraction of the ions have, at a given time, different orientations.

Another way to check this result is to plot the stereographic projection of the $\mathrm{Cl}-\mathrm{O}$ bond orientational probability, or more precisely, to compare this stereographic projection with that obtained for the ideal $T_{d}$ case. As pointed out in [11], this is meaningful only as long as the expansion of the orientational probability density function of the ideal case is truncated at the same $l=10$ value as in the $\mathrm{KClO}_{4}$ case. Figure 1 is drawn, in such a way, for the ideal $\mathrm{T}_{\mathrm{d}}$ case, and figure 2 for $\mathrm{KClO}_{4}$ at $325^{\circ} \mathrm{C}$. In both figures, a strong maximum is found in the (111) direction and this confirms a preferred orientation with $T_{d}$ symmetry. The main difference between figures 1 and 2 is that, in the (110) directions, $P_{0}(\Omega)$ is not zero in $\mathrm{KClO}_{4}$; the fact that, at a given time, $\mathrm{ClO}_{4}^{-}$ions can be found out of the potential wells indicates either that the disorder is dynamic and that the reorientations of the ions are not instantaneous, or that secondary potential wells exist in orientations of $\mathrm{D}_{2 \mathrm{~d}}$ symmetry.

One way to check the second possibility is to examine $P_{0}(\Omega)$ as a function of $\varphi$, which is one of the three Euler angles $(\varphi, \theta, \psi)$ (with the usual

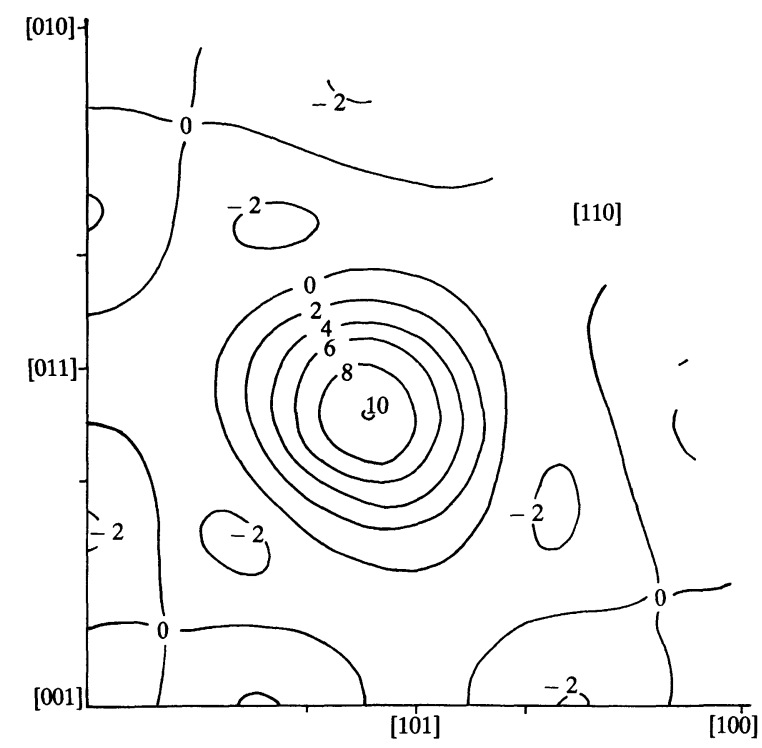

Fig. 1. - Stereographic projection of $T_{d}$, in arbitrary intensity units.

$\begin{array}{ccc}A_{11}^{10} & \left(\AA^{2}\right)\left\langle u_{x}^{2}\right\rangle_{\mathrm{K}^{+}} & \left(\AA^{2}\right)\left\langle u_{x}^{2}\right\rangle_{\mathrm{ClO}_{4}^{-}} \\ - & - & - \\ & 0.101 \pm 0.006 & 0.093 \pm 0.002 \\ 0.10 \pm 0.18 & 0.101 \pm 0.006 & 0.093 \pm 0.002 \\ & 0.119 \pm 0.007 & 0.110 \pm 0.003 \\ -0.04 \pm 0.24 & 0.119 \pm 0.007 & 0.110 \pm 0.003\end{array}$

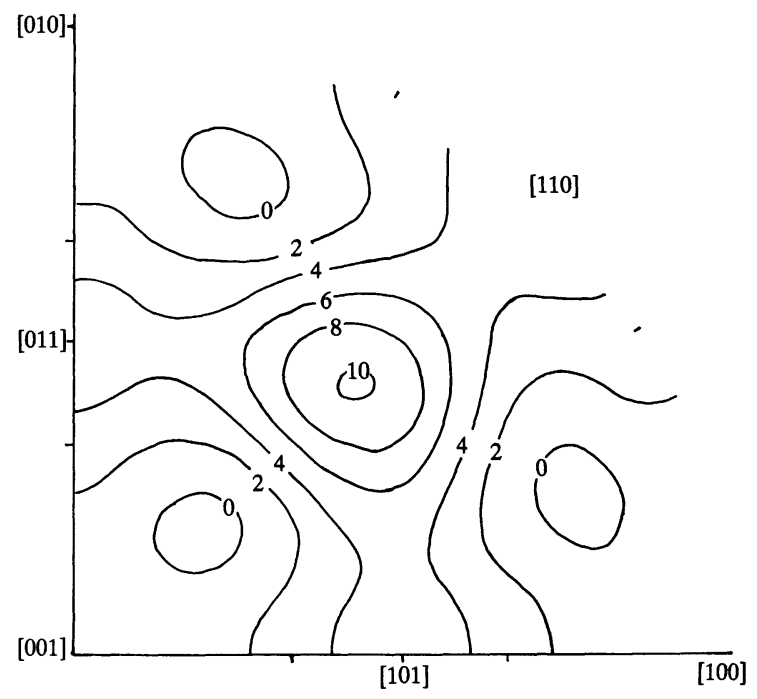

Fig. 2. - Stereographic projection of $\mathrm{KClO}_{4}$ at $325^{\circ} \mathrm{C}$, in arbitrary intensity units.

definition [12]) which characterize the molecular orientation $\Omega$. With $\theta=\psi=0^{\circ}, P_{0}(\Omega)$ should have a maximum for $\varphi=45^{\circ}$ (corresponding to $D_{2 \mathrm{~d}}$ orientation) in addition to the two maxima for $\varphi=0^{\circ}$ and $\varphi=90^{\circ}$ corresponding to the $\mathrm{T}_{\mathrm{d}}$ orientations. Figure 3 shows $P_{0}(\Omega)$ versus $\varphi$ for both

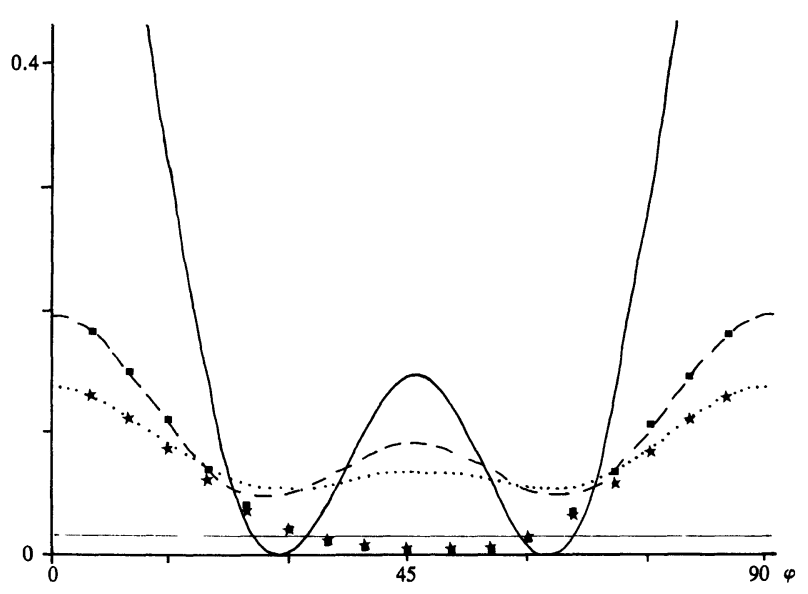

Fig. 3. - Rotation of $P(\Omega)$ obtained from the first model around (100) axis of the crystal : (-) ideal $\mathrm{T}_{\mathrm{d}}$ case ; (-. -) $\mathrm{KClO}_{4}$ at $325^{\circ} \mathrm{C} ;(\ldots ..) \mathrm{KClO}_{4}$ at $420^{\circ} \mathrm{C}$; straight line = isotropy; $(\square) P(\Omega)$ obtained through the libration angles given by the second model at $325^{\circ} \mathrm{C} ;(*)$ idem at $420^{\circ} \mathrm{C}$. 
temperatures. The secondary maximum seen at $45^{\circ}$ is not significant : it is an oscillation caused by the truncation, the curves for $\mathrm{KClO}_{4}$ being below the curve drawn for the ideal $T_{d}$ case, truncated, as above, for $l=10$. Indeed, the expansion of the orientational probability density function is similar in this respect to a Fourier series expansion, well known artefact of which are periodic spurious maxima caused by truncation [11]. The figure shows that ions are present in every position intermediary between the two potential wells of $T_{d}$ symmetry. The existence of an important orientational disorder, superimposed over the $T_{d}$ orientation, is thus confirmed.

In order to check if a model of uniaxial reorientations around a four-fold axis common to the crystal and to the molecule could explain our results, we have calculated theoretical coefficients corresponding to a uniform distribution of molecules around this four-fold axis. Their values are $A_{11}^{4}=0.583$, $A_{11}^{6}=0.125, A_{11}^{8}=0.516$ and $A_{11}^{10}=0.17$, as compared with $A_{11}^{4}=0.44, A_{11}^{6}=0.07, A_{11}^{8}=0.43$ and $A_{11}^{10}=0.10$, found in $\mathrm{KClO}_{4}$. The values are of the same order of magnitude and provide another indication that uniaxial reorientations of $\mathrm{ClO}_{4}^{-}$ions can exist in this crystal.

At $420^{\circ} \mathrm{C}$, all results are similar, except that the maxima of $P_{0}(\Omega)$ along the (111) directions is less intense than at $325^{\circ} \mathrm{C}$ and that the curve of figure 3 comes closer to the straight line corresponding to isotropy : when the temperature increases, disorder increases also and less and less ions are in their equilibrium positions at a given time.

Among the coefficients fitted, are the $\left\langle u_{x}^{2}\right\rangle$ coefficients included in the Debye-Waller factor, corresponding to translation of $\mathrm{K}^{+}$and of $\mathrm{ClO}_{4}^{-}$. At $325^{\circ} \mathrm{C}$, they are found to be : $\left\langle u_{x}^{2}\right\rangle_{\mathrm{K}^{+}}=0.10 \AA^{2}$ and $\left\langle u_{x}^{2}\right\rangle_{\mathrm{ClO}_{4}^{-}}=0.09 \AA^{2}$. At $420^{\circ} \mathrm{C}$, they are : $\left\langle u_{x}^{2}\right\rangle_{\mathrm{K}^{+}}=$ $0.12 \AA^{2}$ and $\left\langle u_{x}^{2}\right\rangle_{\mathrm{ClO}_{4}^{-}}=0.11 \AA^{2}$. The values of $\left\langle u_{x}^{2}\right\rangle_{\mathrm{ClO}_{4}^{-}}$can be compared to the Debye-Waller factor calculated from a Debye model :

$$
\left\langle u_{x}^{2}\right\rangle_{\text {Debye }}=\frac{1}{4 \pi} \sqrt[3]{\frac{3}{\pi}} \frac{a^{2}}{M V^{2}} R T
$$

in which :

$$
R=8.32 \mathrm{~J} \mathrm{~K}^{-1} \mathrm{~mole}^{-1}
$$

$a$ is the cell parameter at temperature $T$

$M$ is the molar mass of $\mathrm{ClO}_{4}^{-}$ion

$V$ is an average sound velocity, taken here to be about $3300 \mathrm{~m} / \mathrm{s}$, which is the value found a few degrees above the transition, in the cubic phase of KCN [13], another orientationally disordered crystal.

$$
\left\langle u_{x}^{2}\right\rangle_{\text {Debye }} \text { is found equal to } 0.020 \AA^{2} \text { at } T=
$$

$325^{\circ} \mathrm{C}$, and $0.024 \AA^{2}$ at $T=420^{\circ} \mathrm{C}$. So, $\left\langle u_{x}^{2}\right\rangle_{\mathrm{ClO}_{4}^{-}}$is approximately five times larger than $\left\langle u_{x}^{2}\right\rangle_{\text {Debye }}$ and increases faster with temperature.

It is thus clear that a simple harmonic translational phonon contribution cannot explain these results. As usual in orientationally disordered crystals, the steric hindrance leads to an important coupling between the orientations of an ion and the positions of its neighbours, which masks completely the temperature dependent translation phonon contribution to the Debye-Waller factor.

On the other hand, one can also, following Press, Grimm and Hüller [14], look for the correlations between the translation and the orientation of the same $\mathrm{ClO}_{4}^{-}$ion. This effect is induced by the neighbouring $\mathrm{K}^{+}$ions, and can be expected to be much smaller than the previous one. Three coefficients of correlation, corresponding to the linear coupling between orientations and translations, were included into the fit ; they correspond to terms with $l=3$ and $l=7$. They were found to be equal to zero within the limit of accuracy, with no changes in the Debye-Waller factors for both temperatures.

\section{Structure of the high-temperature phase : second model and discussion.}

One of the assumption of the previous model is the rigidity of the reorienting ion. This is certainly a crude approximation in the case of $\mathrm{ClO}_{4}^{-}$ions, and a contribution to the structure factor, due to anharmonicity, may be not negligible. If this is the case, one can hope to obtain a better refinement by calculating the structure factor in the way commonly used in crystallographers' atomic model and by introducing explicitly anharmonic coefficients in the development of the temperature factor of the atoms.

Then, the structure factor is equal to:

$$
F(\mathbf{Q})=\sum_{n=1}^{6} f_{n} T_{n}(\mathbf{Q}) \exp \left(i \mathbf{Q} \cdot \mathbf{R}_{n}\right)
$$

where the notations are the same as in (6);n is the number of atoms in the unit cell and $T_{n}(\mathbf{Q})$ is the temperature factor of atom $n$, and is the Fourier transform of the probability density function representing the time averaged displacement $\mathbf{u}_{n}$ of atom $n$ from its equilibrium position. To a first approximation, this probability density function is a Gaussian function, but anharmonicity causes a deviation from the Gaussian shape. The general expression for a harmonic crystal is :

$$
T_{n}(\mathbf{Q})=\exp \left(-\frac{1}{2}\left\langle\mathbf{Q} \cdot \mathbf{u}_{n}^{2}\right\rangle\right)
$$

By putting $\mathbf{Q}=2 \pi \mathbf{H}$

$$
\mathbf{R}_{n}=\sum_{i} x_{n}^{i} \mathbf{a}_{i} \quad\left(\mathbf{a}_{i}\right. \text { is the unit cell edge) }
$$


and expanding $T_{n}(\mathbf{Q})$ up to the third order, the structure factor becomes :

$$
\begin{aligned}
F(\mathbf{H})=\sum_{n=1}^{6} f_{n} \exp \sum_{r s} & \left(2 \pi i x_{n}^{2} h_{r}-\beta_{n}^{r s} h_{r} h_{s}\right) \times \\
\times & \left(1-\frac{4 \pi^{3}}{3} i \sum_{r s t} c_{n}^{r s t} h_{r} h_{s} h_{t}\right)
\end{aligned}
$$

where

$h_{r} h_{s} h_{t}$ represent the Miller indices $h k l$;

$\beta^{r s}$ are the anisotropic temperature factor coefficients ;

$c^{r s t} \quad$ are the anharmonic temperature factor coefficients ;

$\beta^{r s}, c^{r s t}$ are invariant to pair wise interchange of the indices. So in the general case, there are six $\beta^{r s}$ terms and ten $c^{r s t}$ terms for each atom $n$.

In the particular case of $\mathrm{KClO}_{4}$, the calculation was performed with the Prometheus program [15], starting from a few assumptions derived from the results of the first model : the crystal is face-centered cubic $\mathrm{Fm} 3 \mathrm{~m}$ (cell parameter $=7.522 \AA$ ), and the $\mathrm{ClO}_{4}^{-}$ions have two preferred orientations corresponding to $T_{d}$ symmetry. So, the positions of potassium and chlorine atoms are (000) and $\left(\frac{1}{2} \frac{1}{2} \frac{1}{2}\right)$, without any refinement; the oxygen atoms are $(x x x)$ and symmetry corresponding positions (model $32 f[16]$ ), with an occupation factor of 0.5 ; the distance $\mathrm{Cl}-\mathrm{O}$ is thus indirectly fitted. As for the temperature parameters, because of the high symmetry of the crystal, the only non zero coefficients are one $\beta_{r r}$ coefficient for $\mathrm{K}^{+}, \beta^{r r}, \beta^{r s}$, $c^{r r r}, c^{r r s}$ and $c^{r s t}$ for oxygen, and an isotropic factor for Cl [17] : $B=8 \pi^{2}\left\langle u^{2}\right\rangle$.

In a first step, $x, B_{\mathrm{Cl}}, \beta_{\mathrm{K}}^{r r}, \beta_{\mathrm{O}}^{r r}, \beta_{\mathrm{O}}^{r s}$, plus a normalization coefficient were fitted. This leads to six adjustable parameters, the values of which are given in table III, and the structure factor was obtained with a reliability factor $R_{\mathrm{w}}$ equal to $5.9 \%$.

The next step has been to introduce anharmonic coefficients for oxygen atoms, namely $c^{r r r}, c^{r r s}$ and $c^{r s t}$. The weighted reliability factor decreased down to $2.3 \%$. The values of the parameters are given in the third and fifth rows of table III. They are significant but not easy to interpret except by a deformation of the thermal ellipsoid. The structure factors obtained for $T=325^{\circ} \mathrm{C}$, after fitting of the 9 parameters defined above, are listed in table $\mathrm{I}$; most of them are in better agreement with the observed $F_{\text {obs }}$ than the structure factors derived from the first model with the same number of parameters (which is expected since the reliability factor is smaller) but no decisive conclusion can be drawn from this comparison, except that $T_{d}$ orientation is confirmed.

Mean-square displacements can be calculated from the $B$ and $\beta$ 's coefficients. Their values are found to be (for $325^{\circ} \mathrm{C}$ ) : $\left\langle u^{2}\right\rangle_{\mathrm{K}^{+}}=0.103 \AA^{2}$ (as compared to $0.101 \AA^{2}$ in the first model), $\left\langle u^{2}\right\rangle_{\mathrm{Cl}}=$ $0.079 \AA^{2},\left\langle u^{2}\right\rangle_{0}=0.118 \AA^{2}$ and $\left\langle u_{\perp}^{2}\right\rangle_{0}=0.272 \AA^{2}$. (// and $\perp$ indexes refer to the $\mathrm{Cl}-\mathrm{O}$ bond). At $420{ }^{\circ} \mathrm{C},\left\langle u^{2}\right\rangle_{\mathrm{K}^{+}}=0.116 \AA^{2}\left(0.119 \AA^{2}\right),\left\langle u^{2}\right\rangle_{\mathrm{Cl}}=$ $0.089 \AA^{2},\left\langle u \|^{2}\right\rangle_{0}=0.134 \AA^{2}$ and $\left\langle u_{\perp}^{2}\right\rangle_{0}=0.309 \AA^{2}$. From $\left\langle u_{\perp}^{2}\right\rangle_{0}$, the librational angle is found to be $\simeq 20^{\circ}$ at $325^{\circ} \mathrm{C}$ and $\sim 22^{\circ}$ at $420^{\circ} \mathrm{C}$. These very high values are an indication that the disorder is not purely static and that the $\mathrm{ClO}_{4}^{-}$ions have a strong tendency to reorient between their preferred mean positions. They are also larger than the resolution of the cubic rotator of order 10 used in the first model $\left(\sim 18^{\circ}\right)$. To calculate the three coefficients of order 12 in the development of $P_{0}(\Omega)$, if it were reasonable, would probably not add more details to the results.

We have checked (Fig. 3) that if we assume as in the Prometheus program that $P(\Omega)$ is Gaussian, centered on the $T_{d}$ orientations with halfwidths $20^{\circ}$ and $22^{\circ}$, the resulting profiles agree very well with the o.p.d.f. expansion model in regions not too far from the equilibrium orientations. This confirms that both descriptions are consistent in those regions. The disagreement is large far from the equilibrium

Table III. - Parameters of the second model.

\begin{tabular}{|r|r|r|c|c|c|c|c|c|}
\hline \multicolumn{1}{|c|}{$B_{\mathrm{Cl}}$} & \multicolumn{1}{c|}{$\boldsymbol{\beta}_{\mathrm{K}}^{r r}$} & \multicolumn{1}{c|}{$\boldsymbol{\beta}_{\mathrm{O}}^{r r}$} & $\beta_{\mathrm{O}}^{r s}$ & $c_{\mathrm{O}}^{r r}\left(\times 10^{3}\right)$ & $c_{\mathrm{O}}^{r s}\left(\times 10^{3}\right)$ & $c_{\mathrm{O}}^{r s t}\left(\times 10^{3}\right)$ & $d(\mathrm{Cl}-\mathrm{O})(\AA)$ & $T$ \\
\hline 5.858 & 0.037 & 0.074 & -0.018 & & & & 1.316 & $325^{\circ} \mathrm{C}$ \\
\pm 0.356 & \pm 0.003 & \pm 0.004 & \pm 0.002 & & & & \pm 0.026 & \\
6.202 & 0.036 & 0.077 & -0.018 & -0.179 & 0.033 & -0.027 & 1.264 & \\
\pm 0.152 & \pm 0.001 & \pm 0.003 & \pm 0.001 & \pm 0.033 & \pm 0.004 & \pm 0.006 & \pm 0.026 & \\
\hline 7.019 & 0.048 & 0.075 & -0.015 & & & & 1.326 & $420{ }^{\circ} \mathrm{C}$ \\
\pm 0.393 & \pm 0.004 & \pm 0.004 & \pm 0.001 & & & & \pm 0.026 & \\
7.051 & 0.040 & 0.087 & -0.020 & -0.204 & 0.027 & -0.023 & 1.221 & \\
\pm 0.129 & \pm 0.001 & \pm 0.005 & \pm 0.001 & \pm 0.057 & \pm 0.005 & \pm 0.008 & \pm 0.026 & \\
\hline
\end{tabular}


orientations because of the principle of Prometheus program and of the truncation of $P(\Omega)$ in the first model.

The distance $\mathrm{Cl}-\mathrm{O}$ calculated in this second model is very short $(\sim 1.32 \AA)$ and unrealistic, as compared to $\sim 1.5 \AA$ found previously and to the distances found in the low temperature orthorhombic phase, which vary from $1.4 \AA$ to $1.44 \AA$ (the $\mathrm{ClO}_{4}^{-}$tetrahedron is slightly distorted in this phase). To find too short a distance is usual in this kind of model [17], and is due to the deformation of the thermal vibrational ellipsoid by anharmonicity. Moreover, because of the high values of $\left\langle u^{2}\right\rangle_{\mathrm{Cl}}$ and $\left\langle u^{2}\right\rangle_{\mathrm{O}}$, the mean instantaneous distance can vary considerably.

\section{Conclusion and final remarks.}

This experiment confirms the result obtained by Klein et al. by molecular dynamics simulation, concluding that $\mathrm{ClO}_{4}^{-}$ions have preferred orientation of $T_{d}$ symmetry in the high temperature phase of $\mathrm{KClO}_{4}$. Theses authors calculated values for the coefficients of order 4 and 6 of the symmetry adapted functions; once transformed into coefficients of the cubic rotators, those are : $A_{11}^{4}=$ 0.366 , but $A_{11}^{6}=0.203$ which is much higher than our very small $A_{11}^{6}$. This difference may come from the potential they used. The disorder is higher than that predicted by their force model, even at a few degrees above the transition temperature.

As for the experiment of Toupry et al., our discussion of the phase transition explains their incorrect result : it was obtained from an analysis of the relative intensity of an internal mode of the $\mathrm{ClO}_{4}^{-}$ion in two different scattering geometries. This leads to a direct measurement of $A_{11}^{4}$, and they deduced an orientation of $\mathrm{C}_{3 \mathrm{v}}$ symmetry from a negative sign of this coefficient. As the Raman scattering geometries are related to the crystal axes, the method implies knowledge of the crystal orientation, which they had not. As we have seen in section 2, contrary to Toupry et al. assumption, this orientation cannot be predicted and several orientations may coexist. It is thus not possible to relate their measurements to our present and more refined knowledge of the structure and/or of the phase transition. One can simply conclude from the anisotropy they detected that, as in our experiments, their high temperature specimen was formed of a small number of crystallites.

Our experiment dealing with the static orientation probability density function, it is of course not possible to give definite conclusions about the dynamical aspect of the disorder. But, because of the presence of many ions in orientations of $T_{d}$ symmetry and of quite a number of ions out of the potential wells, and also because our very small value of $A_{11}^{6}$ is consistent with the theoretical value of
$A_{11}^{6}$ calculated for a uniaxial rotation of a tetrahedron, we are tempted to conclude that, in $\mathrm{KClO}_{4}$, ions reorient mainly between their two potential wells by rotations around the (100) axes of the crystal. This is confirmed by figure 4 in which are drawn on a stereographic projection, the reorientational paths of an oxygen atom during rotations around the three four-fold axes of the crystal [18]. The relatively high probability of presence of oxygen atoms in the region (110) is clearly visible.

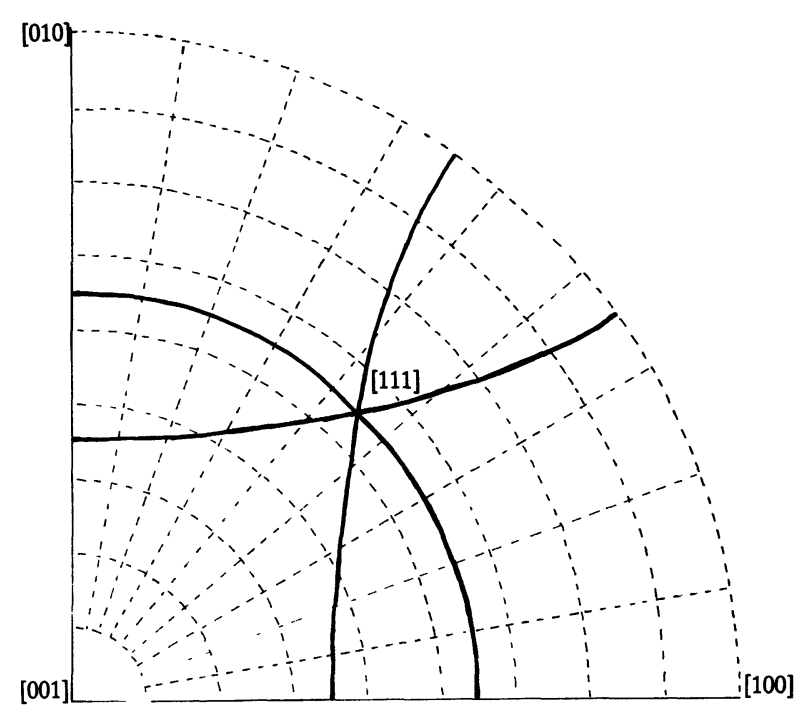

Fig. 4. - Theoretical reorientational paths of an oxygen atom during rotation around the three four-fold axes of the crystal.

A short comparison between the results obtained by the two methods used to analyse our data can now be made. Both models agree on the preferred orientation of the molecules (a fit assuming a $\mathrm{D}_{2 \mathrm{~d}}$ orientation in the second model lead to a poor reliability factor) and on large oxygen motions perpendicular to the $\mathrm{Cl}-\mathrm{O}$ bond. The first model strongly tends towards the reorientational process described above. The second model provides an estimate of the mean deviation of the $\mathrm{Cl}-\mathrm{O}$ bond from its preferred orientation; this value is so large that the resolution $(l=10)$ of the first model turns out to be sufficient to describe our data. This is not always the case, as Depondt et al. have shown in the case of neopentane [19].

Before closing this section, let us point out that the present study stresses the importance of detailed structure analyses of the ionic ODIC phases. Indeed, though both $\mathrm{KClO}_{4}$ and $\mathrm{NaClO}_{4}$, have the same f.c.c. structure in their plastic phase, the maximum of $P_{0}(\Omega)$ corresponds to a $\mathrm{D}_{2 \mathrm{~d}}$ orientation in the latter case [20], contrary to the $T_{d}$ orientation found here. From a purely steric point of view, one would 
expect the $\mathrm{Cl}-\mathrm{O}$ bond always to point towards the center of a potassium octahedron face, i.e. in the (111) direction. This is indeed the situation with the $\mathrm{K}^{+}$ion, but not with the smaller $\mathrm{Na}^{+}$ion, where a strong orientation translation coupling allows for a different preferred orientation. The same situation had already been encountered with the alkali cyanides, and detailed numerical simulations [21] showed that, in the latter case, no simple interionic potential was able to reproduce, at once, the high and low temperature structures of these crystals. More work needs to be done to see if the situation is easier to model in the case of the $\mathrm{ClO}_{4}^{-}$corresponding phases.

\section{References}

[1] Johansson, G. B. and Lindovist, O., Acta Crystallogr. B 33 (1977) 2918.

[2] Pistorius, C. W. F. T., J. Phys. Chem. Solids 31 (1970) 385.

[3] Press, W. and Huller, A., Acta Crystallogr. A 29 (1973) 252.

[4] Guthrie, G. B. and McCullough, J. P., J. Phys. Chem. Solids 18 (1961) 53.

[5] Toupry, N., Poulet, H., Le Postollec, M., Pick, R. M. and YvineC, M., J. Raman Spectros. 14 (1983) 166.

[6] KLEIN, M. L., MCDonald, I. R. and OsAKI, Y., J. Chem. Phys. 79 (1983) 5579.

[7] Venkateswara RaO, A., Bull. Mater. Sci. 7 (1985) 83.

[8] Bradley, C. J. and Cracknell, A. P., The mathematical theory of symmetry in solids (Oxford) 1972.

[9] AmoureuX, J. P. and BeE, M., Acta Crystallogr. $B 36$ (1980) 2636.

[10] Yvinec, M. and Pick, R. M., J. Phys. France 41 (1980) 1045.
[11] Denise, B., Depondt, Ph., Debeau, M. and SCHweISS, P., J. Phys. France 48 (1987) 615.

[12] LYUBARSKII, The application of group theory in physics (Pergamon Press, London) 1960, p. 12.

[13] Boissier, M., VACHER, R., FonTAINE, D. and PICK, R. M., J. Phys. France 39 (1978) 205.

[14] Press, W., Grimm, H. and Huller, A., Acta Crystallogr. A 35 (1979) 881.

[15] Zucker, U., Perenthaler, E., Kuhs, W. F., BaChmanN, R. and SchulZ, H., J. Appl. Crystallogr. 16 (1983) 358.

[16] International Tables for X-ray Crystallography (Birmingham) 1952, p. 338.

[17] Willis, B. T. M. and PRYOR, A. W., Thermal vibrations in crystallography (Cambridge University Press) 1975.

[18] BREYMANN, W., private communication.

[19] Depondt, Ph. and Debeau, M., J. Phys. France 48 (1987) 1513.

[20] Berthold, H. J., KRUSKa, B. G. and Wartchow, R., Z. Naturforsch. Teil B 34 (1979) 522.

[21] Klein, M. L. and McDonald, I. R., J. Chem. Phys. 79 (1983) 2333. 